\title{
THE PRESENT STATUS OF RADIOTHERAPY AND CHEMOTHERAPY IN THE TREATMENT OF CHRONIC LEUKAEMIA
}

\author{
A Review
}

By M. HULBERT, F.F.R.

Director, Radiotherapy Department, St. Mary's Hospital, London

TABLE I

\begin{tabular}{|c|c|c|c|c|c|c|c|c|c|c|c|}
\hline Year & & I 940 & 1941 & 1942 & I 943 & 1944 & I 945 & 1946 & 1947 & 1948 & 1949 \\
\hline Deaths from all types of leukaemia & $\cdots$ & 1,050 & 962 & 1,087 & $\mathbf{1}, \mathbf{1} 47$ & 1,185 & 1,284 & 1,419 & 1,452 & 1,484 & 1,703 \\
\hline Death rate per million population & . & 26 & 25 & 28 & 30 & $3 \mathbf{I}$ & 34 & 35 & 35 & 35 & 40 \\
\hline
\end{tabular}

Deaths from Leukaemia in England and Wales, 1940-49

Leukaemia was first recognized as a disease entity just over a century ago and since then a great deal has become known about its clinical and pathological features. The progress in accurate diagnosis and in the correlation of the clinical manifestations with morbid anatomical changes has, however, not been equalled by an increased knowledge of the causation of the disease, its prevention or cure; thus the problem of the treatment becomes ever greater with its steadily increasing incidence which is reflected in the mounting death rate (Table $\mathrm{I}$ ).

Leukaemia is incurable by present-day methods, but it is not untreatable. In many instances it is possible to supress the manifestations of the disease for periods of months or even years. Important palliation is thereby achieved which enables the sufferer from chronic leukaemia to remain free from symptoms for the greater part of his allotted span of life.

The agents used in the treatment of chronic leukaemia are cell poisons which, while differing in their detailed mode of action, have yet in common a particularly strong action on cells with a high rate of division and of nucleoprotein metabolism. Their action results in delay or suppression of mitosis, and causes death or degeneration of a cell either immediately or during subsequent mitosis. In germ cells there is also an increase in the rate of mutation amongst the survivors. This pattern of action was first discovered in the case of $\mathrm{X}$-rays and of other ionizing radiations, but in recent years some 'radio-mimetic' chemicals have been found and others synthesized. They have been, and are being, subjected to laboratory tests for their action on normal and neoplastic tissues, and a number of them have been taken into clinical use. In spite of considerable progress only temporary effects can be obtained in leukaemia and repeated treatments are necessary. There is also as yet no ray or drug which will damage leukaemic cells to the exclusion of others, and the treatment of leukaemia by present-day methods must be supervised meticulously, not only because some forms of treatment have unpleasant side effects, but also because all of them are otherwise liable to inflict irreparable damage on the production of normal blood cells and platelets.

The clinical response follows much the same pattern whichever agent is employed. When it is satisfactory there is an improvement in both signs and symptoms. During such a remission the patient's general condition rallies with the cessation of lassitude, pyrexia, loss of weight, and joint pains. Local symptoms diminish with the reduction of the splenic swelling, of lymph node enlatgements, and of other leukaemic infiltrations. The degree of leukaemic change in the bonematrow diminishes, and this is reflected in the peripheral blood in a return to a more normal picture with a fall in the abnormally raised number of leucocytes and a possible complete disappearance of abnormal cells (Figs. I and 2), also the number of platelets readjusts to a more normal level; but most important of all is an increase in red-cell 


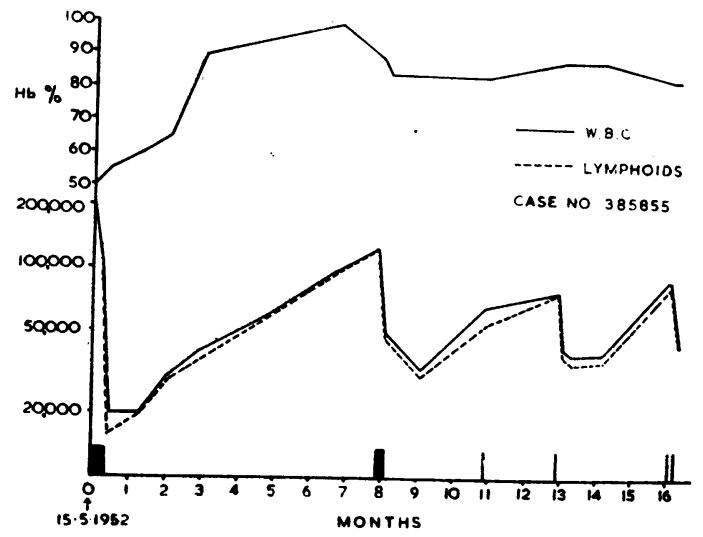

FIG. 1.-Chronic Lymphatic Leukaemia. Response to splenic X-ray irradiation. Courses of treatment indicated on bottom line.

production with a rise of the haemoglobin level to a near normal figure because the improvement in the patient's general condition depends in most cases upon the lessening of the anaemia rather than upon a reduction of the white-cell count as such. These two are, however, connected because the maximum recovery of erythropoiesis occurs only after the leukaemic process has been damped down sufficiently to effect a substantial reduction in the number of circulating leucocytes. This is especially noticeable in myeloid leukaemia where reduction of the white-cell count to normal levels is generally necessary for a satisfactory remission. The return of normal red-cell production is also of shert-term prognostic significance because it proves that this function of the bone marrow has not been damaged irreparably by either the disease or by its treatment.

\section{Radiotherapy}

$X$-Rays. It has long been known that lymphoid and myeloid tissues are particularly prone to suffer damage by exposure to $\mathrm{X}$-rays and other ionizing radiations. This results clinically in a fall of the white-cell count, and led to the use of $\mathrm{X}$-rays in the treatment of chronic leukaemia as early as 1902.1 X-ray therapy has, indeed, remained to this day the most commonly used ' all-round' method of treatment of this condition.

Satisfactory remissions can be obtained by irradiation of the whole patient with doses which are too small to have any marked effect on the blood count of a normal person. This can be attributed to direct irradiation damage of the leukaemic tissues which are particularly radiationvulnerable by virtue of their reversal to a more primitive type with an abnormally' high rate of cell division. Irradiation may also damage some

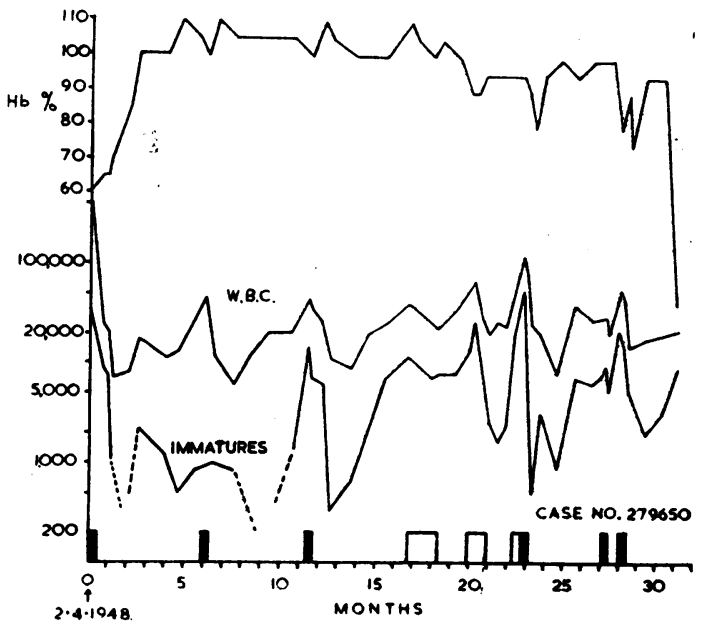

FIG. 2.-Chronic Myeloid Leukaemia. Response to splenic X-ray irradiation and to urethane courses of treatment indicated on bottom line (solid marking shows X-ray therapy).

of the circulating white blood cells, but these are generally much more resistant to irradiation than their precursors in the tissues. ${ }^{2}$ Remissions are also obtained by irradiation of only a part of the body, and irradiation of the spleen has the most certain and specific effect in both myeloid and lymphatic leukaemia. The reduction of the splenic swelling is probably due to a direct effect of the X-rays, but it is still unexplained how splenic irradiation causes a reversal of the marrow picture to a more normal pattern. ${ }^{3,4}$

Irradiation will benefit the vast majority of sufferers from chronic myeloid leukaemia as judged objectively by the control of the splenic swelling and of the anaemia, and about one in three cases of chronic lymphatic leukaemia with anaemia will also show an increase in haemoglobin after irradiation. This contrasts with the occurrence of spontaneous remissions in 5 per cent. of patients with chronic lymphatic ${ }^{5}$ and 7 per cent. of patients with chronic myeloid leukaemia. ${ }^{6}$ In lymphatic leukaemia the pressure symptoms caused by enlarged lymph nodes or by other massive infiltrations can be controlled in most instances by local irradiation; but these lesions are not as highly ' radio-sensitive' as used to be widely believed. The slowly progressing form of chronic lymphatic leukaemia which occurs in the elderly without causing gross enlargement of spleen or lymph nodes and which is not associated with a high degree of anaemia, will hardly clamour for any active treatment.! In some of these cases the white blood count is very high, i.e. 80,000 to 100,000 , and a reduction to more normal levels is indicated because most patients will feel better 
for it. They occasionally report back on their own initiative some time after this and it is then found that the recurrence of malaise coincides with a renewed rise of the white-cell count to a high level.

The subleukaemic and aleukaemic forms of leukaemia seldom do well on irradiation, because even most cautious dosage is liable in these conditions to depress the normal production of red cells or of neutrophils. This is also seen at the end stages of cases of chronic leukaemia which had previously remained controlled for some time by irradiation. Radiotherapy is of no value in the acute terminal stages of chronic leukaemia or in acute leukaemia.

Radiotherapy has no proved effect on the duration of chronic leukaemia, which remains at a mathematical mean of three years with wide individual variations from a few months to over five years. ${ }^{10,}{ }^{39}$ Statistics, however, cannot indicate the great palliative effect which enables most patients to live useful lives until very shortly before their demise.

Dosage. In the majority of cases the initial course of radiotherapy is given with the view to obtain a remission by a reduction of the white blood count. Experience has shown that a reduction to near normal limits over a period of at least two to four weeks is to be aimed at. Especially in myeloid leukaemia a lesser degree of reduction is rarely followed by a remission of satisfactory duration. A more rapid reduction of a high white blood count is difficult to control and might end in general marrow failure. A rapid disintegration of a large bulk of leukaemic cells is also liable to cause sickness, and may lead to renal damage from hyperuricaemia. 7,8

Conventional high voltage therapy ( $180-250 \mathrm{kV}$.) is employed, and amounts from 50 to 200 r. per session are given to the spleen from front, back, and side through fields measuring $200-300 \mathrm{~cm}^{2}$ Treatment is given daily, or at least twice a week. ${ }^{\circ}$ Alternatively, the whole body is exposed to doses of 10 to $30 \mathrm{r}$. per session at weekly or fortnightly intervals. ${ }^{10}$ The response varies individually. The exact dose and intervals of treatment have to be adjusted in the light of full blood counts which must be taken before each treatment. Unless there is a further fall in the haemoglobin or in platelets, the treatment is continued until it is estimated that the ultimate reduction of the white blood count will reach 8,000 to 10,000 , taking into consideration that the level will continue to fall for a few days after the treatment is stopped. After the reduction of the white blood count by total body or splenic irradiation, it may still be necessary, in lymphatic leukaemia, to give local irradiation to enlarged lymph nodes or to massive leukaemic infiltration. For this, single repeated doses of the order of $300 \mathrm{r}$. are employed.

The first remission after irradiation may last for weeks or months, and the patient's progress is followed by monthly re-examinations, including a full blood count. Further treatment is given whenever an exacerbation of the leukaemic process is seen either in the patient's general condition, a fall in haemoglobin, or an accelerated increase of leucocytes or of their primitive forms. The aim is to maintain, by repeated small courses of treatment, the optimum state of health which was gained after the initial course. There is no ground for believing that radiotherapy should be held in reserve as long as possible on the assumption that only a set total number of treatments can be applied to any particular patient with any measure of success. The maintenance treatments are similar to the initial treatment, but the individual response at each treatment series must be ascertained anew by repeated blood counts. Sometimes, transient phases of a poor radiation response are observed during which radiotherapy seems ineffective, whereas a further course a few weeks later is followed by the desired result. This observation throws some doubt on the value of comparing the effects of different treatment. methods by their trial in the same patient at different times. Sooner or later, however, every case will enter into the terminal and untreatable stages of the disease with the development of either progressive anaemia, general marrow failure, or an acute leukaemic crisis.

\section{Radioactive Phosphorus}

Ordinary phosphorus with the atomic mass of 31 can be made to acquire the mass of 32 by the artificial introduction into its nucleus of one neutral particle of unit mass (neutron). This change does not affect the chemical behaviour of phosphorus, but the nucleus of the isotope, $\mathbf{P}^{32}$, is physically unstable and is bound to break down. This breakdown, which transforms $\mathrm{P}^{32}$ to ordinary sulphur, is accompanied by the emission of Betaradiation. This change does not occur simultaneously in all the $\mathrm{P}^{32}$ atoms present and the number of disintegrations and the intensity of the accompanying Beta-radiation decreases exponentially, reaching half the original value after $14-3$ * days-the half life of $\mathrm{P}^{32}$ - one-quarter of the: original value in a further 14.3 days and so on.

$\mathrm{P}^{32}$ is metabolized like ordinary phosphorus and is taken up by different tissues according to their total phosphorus content, rate of turnover, and mitotic activity. After intravenous administration the amount not used in the body is excreted in the urine, and after oral administration, also in the faeces. It was expected that leukaemic cells 
would take up $\mathrm{P}^{32}$ with avidity for use in their high nucleoprotein metabolism, and it was hoped that on doing so they would commit suicide by irradiation. In leukaemic subjects the highest concentrations of $\mathrm{P}^{32}$ do in fact coincide with the sites of leukaemic infiltration after the erythrocytes have held most of it for the first day or two. The ultimate preferential uptake in bone marrow, liver, spleen, and kidneys is one of degree only; and irradiation changes are found also in lungs, gastro-intestinal tract and gonads. Even if $\mathbf{P}^{32}$ were picked up exclusively by leukaemic cells, the penetration of its Beta-radiation up to $7 \mathrm{~mm}$. into the surrounding tissues would still subject the erythropoietic tissue in the bone marrow to a great deal of unavoidable irradiation. It is therefore not surprising that the results of $\mathrm{P}^{32}$ treatment in leukaemia are akin to those of whole body irradiation by $\mathrm{X}$-rays. ${ }^{11}$

Dosage. $\mathrm{P}^{32}$ is used in the form of $\mathrm{Na}_{2} \mathrm{HPO}_{4}$ in an isotonic watery solution. It is given intravenously, or else orally on an empty stomach in doses 1.3 times the intravenous dose. The intravenous dose-range for the treatment of chronic leukaemia lies between 0.5 to $1.5 \mathrm{mc}$. twice a week. The dose control is similar to that used in X-ray therapy, but the administration of $\mathbf{P}^{32}$ has to be discontinued sooner because the effective radio-activity of the last dose of $\mathbf{P}^{32}$ goes on for some days. Long courses of therapy lasting up to four or six weeks may be necessary, especially in chronic lymphatic leukaemia in which condition it is also frequently indicated to supplement the general irradiation by local X-ray therapy to enlarged lymph nodes or viscera. ${ }^{12,}{ }^{13}$

\section{Supplementary Treatment}

Iron. The anaemia of leukaemia is not caused by iron deficiency, but it is customary to prescribe iron in order to exclude a deficiency during the time of increased erythropoiesis in a remission.

Blood transfusion. This is indicated when erythropoiesis: fails to increase after a satisfactory response of the white-cell count during the first course of treatment. The increased haemoglobin level after transfusion may be retained for many months in which case further transfusion would be useful.

Splenectomy. Splenectomy is to be considered where a serious degree of thrombocytopenia or of haemolytic anaemia persists in spite of an otherwise satisfactory. response to irradiation. ${ }^{14}$

\section{Chemotherapy}

The substances which have been used in the treatment of chronic leukaemia include arsenic, benzol, heavy metals, phosphorus, amidopyrin, thiouracil, leucotoxins, and leucolycins. Their. action is uncertain, short-lived, or associated with toxic side effects. Arsenic was in common use until it was realized that X-ray therapy could still produce remissions when arsenic had become ineffective. In such cases, however, radiotherapy was liable to be complicated by severe constitutional symptoms and by splenic pain. Although this does not apply to benzol, this drug has not found general favour. ${ }^{15}$

\section{Urethane}<smiles>CCC(N)=O</smiles>

Ethylcarbamate (urethane).

Urethane has been in use for a considerable time as an anaesthetic for laboratory animals. It has also been known that urethane suppresses the mitoses of their corneal cells and also lowers their white blood count. ${ }^{16}$ These effects and the suppression by urethane of the growth of simple organisms, as well as its mutagenic action in the fruit-fly, suggested a pattern of action similar to that of ionizing radiations and led in 1946 to the investigation of the influence of urethane on animal tumours. ${ }^{17}$ This confirmed the inhibition of cell division and of growth, and also.showed an enhancement of the differentiation process in animal tumours to a greater degree than that associated with a similar retardation of growth produced by other chemicals. A return of the abnormal respiration and glycolysis of leukaemic blood cells in vitro to a more normal pattern has also been observed. ${ }^{18}$ The basic action of urethane is thought: to be an interference with purine metabolism and an inhibition of the normal synthesis of nucleinic acid.

Clinical trials ${ }^{19,20,21,22}$ have demonstrated the effect of urethane on leukaemia to be similar to that obtained by $\mathrm{X}$-rays. The remissions, however, are not usually as lasting as those following radiotherapy, ${ }^{23}$, nor are they as a rule as satisfactory as judged by the return of normal red-cell and platelet production. It is not generally of value in cases which have ceased to respond to irradiation. Immediate toxic effects like nausea and vomiting occur in about half the patients treated by urethane and there is also a danger of marrow aplasia and liver damage with prolonged administration. ${ }^{23 \mathrm{~A}}$ Urethane has therefore not proved to be an advance on radiotherapy in leukaemia and its clinical use is now mainly restricted to the treatment of multiple myelomatosis.

Dosage. Urethane is conveniently dispensed in a watery solution containing $\mathrm{I} g$. per dose and flavoured with syrup of orange to disguise its taste. The daily dose varies from 2 to $5 \mathrm{~g}$. 
When used in doses of $3 \mathrm{~g}$. per day a fall of the white-cell count can be observed within five to seven days, and in the average case of leukaemia with a very high initial count a level of 20,000 is reached in four weeks. The wide individual variation, however, demands careful supervision as in X-ray therapy.. There is no advantage in continuing a small daily maintenance-dose once an improvement is obtained. Treatment is recommenced on the same indications as in radiotherapy.

\section{Nitrogen Mustard}

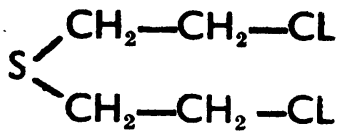

Bis (chloroethyl) sulphide Mustard gas.<smiles>CN(CCCl)CCCl</smiles>

Methyl-bis ( $\beta$-chloroethyl) amine

Bis-nitrogen mustard or $\mathrm{HN}_{2}$.<smiles>ClCCN(CCCl)CCCl</smiles>

Tris $(\beta$-chloroethyl) amine Tris-nitrogen mustard.

War-time research into the pharmacological action of mustard gas and its derivatives showed that the systemic administration of the nitrogenous analogues of mustard gas was followed by damage to body tissues, generally in proportion to their cellular proliferation. Lymphoid tissues, bone marrow, intestinal mucosa and gonads are the most sensitive. Large doses damage all elements of the bone marrow; smaller therapeutic doses produce a transient lymphopenia which is most pronounced in about one week and a transient neutropenia and thrombocytopenia which are most marked in two to three weeks. Local irritation of the gastro-intestinal mucosa is produced by oral administration, and it is therefore necessary to give nitrogen mustard intravenously. The local toxic action is liable to cause venous thrombosis, and local necrosis may follow in case of extravasation. Heachache, some degree of nausea and even vomiting occurs not uncommonly within a few hours after administration.

Nitrogen mustard salts are unstable in watery solution. They undergo reversible chemical rearrangements, one of which is the formation of highly reactive cyclic imonium cations.

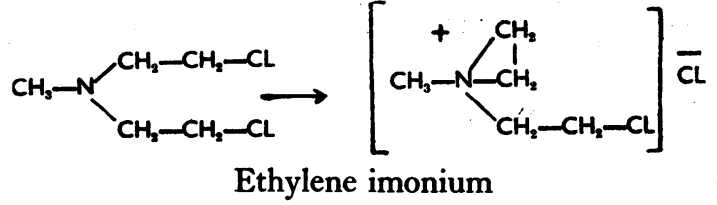

These act as alkylating agents and attach themselves to carboxyl- and amino-groups of proteins. They also inhibit cellular enzymes like phosphokinase and probably also peptidase. An interference with normal desoxyribonucleic acid synthesis in cells can be demonstrated and is regarded as an important cause of the observed inhibition of mitoses, nuclear fragmentation and chromosomal aberration. ${ }^{24}$

Clinical trials with nitrogen mustard have been carried out since $1946 .{ }^{25}, 26,27,28$ There is no useful effect in acute leukaemia. Remissions will result in the majority of new cases of chronic myeloid leukaemia, but the improvement is liable to be of short duration and splenic enlargement may return within a month or so, even under continued treatment. ${ }^{25}$ The most satisfactory response is obtained in the slowly progressive type of chronic lymphatic leukaemia. There is no conclusive evidence that the drug will be effective in cases where the disease has ceased to respond to radiotherapy. The long-term results of treatment with tris-nitrogen mustard prove that chronic leukaemia can be controlled for long periods by repeated courses and that in skilled hands there is little danger of causing marrow aplasia by this treatment.

Dosage. The initial dose in the average adult is 6mg. of nitrogen mustard. This can be repeated in three or four days' time unless there is a marked reduction in the white blood cells during this short interval. The response is followed closely with repeated full blood counts and further treatment given as indicated. Injections at three to four weeks' intervals are not uncommon.

The drug is used immediately after solution in normal saline and venous thrombosis is prevented by injection into a fast running saline drip. It is customary to give drugs of the anti-sea sickness group because about 20 per cent. of cases experience troublesome nausea a few hours after the injection.

\section{R 48}

The drawback of nitrogen mustard lies in its toxic side effects and in that it has to be given by intravenous injection. A large number of nitrogen mustard derivatives were therefore investigated and the aromatic analogue $R 48$ was subjected to clinical trials ${ }^{30,} 31$ because it can be taken by 
mouth and does/not cause severe toxic symptoms.

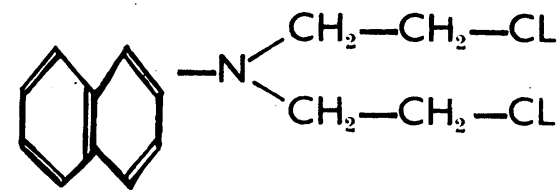

$\beta$-naphthyl di-2-chloroethylamine ( $\left.R{ }_{4} 8\right)$ Unfortunately, it is not very effective and its action is uncertain. There are, however, some cases of chronic leukaemia in which it has proved useful. The drug is given in tablets of $50 \mathrm{mg}$. and daily doses of 200 to $300 \mathrm{mg}$. are given. The reduction of the white blood count takes place slowly and the drug is discontinued at the desired level. It is not useful when used in smaller doses as a daily maintenance.

\section{TEM}

TEM owes its nitrogen mustard-like action to three ethylenimino groups which are similar to those of the reactive transformation product of nitrogen mustard.

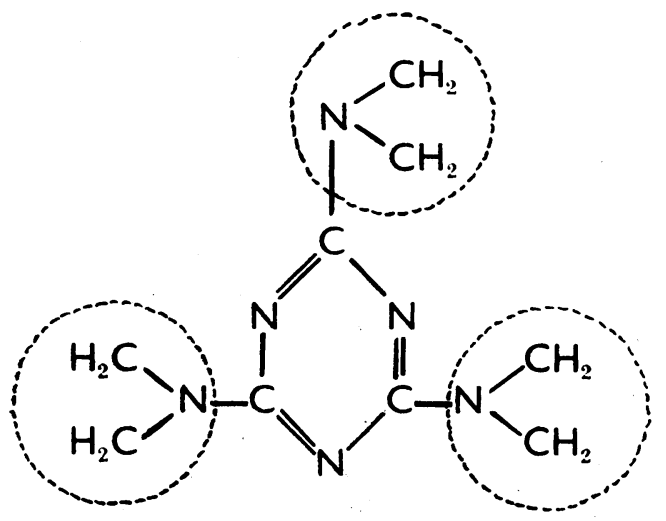

2,4,6 Triethylenimino-s-triazine

(triethylenemelamine-TEM)

Its clinical use is the result of independent and simultaneous investigations in this country and in America. The damaging effect of TEM on bone marrow and lymphoid tissues is more prolonged than that of nitrogen mustard and limits its use because of the danger of marrow aplasia. Unlike nitrogen mustard, it can be given by mouth and it does not often cause nausea or vomiting. It is unstable in acid solution and the variable inactivation by gastric juice is prevented by its administration in enteric-coated tablets. Even so, the exact degree of marrow depression is unpredictable and has to be ascertained in each individual case after an initial safe dose has been given.

Clinical trials show that TEM is capable of producing remissions in chronic myeloid and lymphatic leukaemia. ${ }^{32,}$ 33, 34, 35 A considerable proportion of patients developed marrow aplasia during the early trial period before safe dose limits were established, but there is still doubt as to the danger of bone-marrow damage by repeated administration of TEM over a long period of time even with smaller doses. The clinical response of myeloid leukaemia follows the pattern seen with irradiation. Patients, who after prolonged control by irradiation had reached a refractory stage, have not materially benefited by TEM. In lymphatic leukaemia, however, some encouraging results have been obtained in cases of a type which do not usually respond well to irradiation, as for instance, patients with neutropenia, severe anaemia, ${ }^{33}$ or radio-resistant lymph node enlargement. There is, however, no general superiority of TEM over irradiation in lymphatic leukaemia, and some cases have responded well to $\mathrm{X}$-ray therapy after an initial poor response to TEM. ${ }^{35}$

Dosage. The initial dose in leukaemic patients should not exceed 0.1 to $0.2 \mathrm{mg}$. per $\mathrm{kg}$. bodyweight, the smaller dose being recommended in the chronic lymphatic type. The dose is spread over a few days in order to prevent nausea which might follow one single massive dose. The clinical effect is followed closely by weekly examination with blood counts. The white-cell count, haemoglobin, and platelet count taken at the end of the third week will indicate whether a further dose may be given. Further doses are given as required and treatment at two to four .weeks' intervals is not unusual.

The ease of administration and the absence of immediate severe toxic side effects must not detract from the necessity of very close supervision if marrow damage is to be avoided.

\section{Myleran}

Sulphonic acid esters have, like nitrogen mustards, an ability to become linked to some body constituent by alkylation. A range of these compounds was therefore investigated for their depressive action on tumours and on normal tissues of animals. In a series of homologues it was found that myleran was not only the most active depressant on tumours and on neutrophil production but that it had very little effect on normal lymphocyte formation. ${ }^{36}$

\section{$\mathrm{CH}_{3} \mathrm{SO}_{2} \mathrm{O}\left(\mathrm{CH}_{2}\right)_{4} \mathrm{OSO}_{2} \mathrm{CH}_{3}$}

I :4 Dimethanesulphonyl-oxybutane (Myleran)4 This unusual selective effect led to the use of Myleran in myeloid leukaemia. ${ }^{37}, 38,39$ It can be given by mouth and does not cause nausea or vomiting. The initial remissions obtained in 
cases of chronic myeloid leukaemia seem to be more satisfactory and longer lasting than those usually obtained after treatment with other drugs. In a few cases remissions can be obtained after the disease has ceased to respond satisfactorily to irradiation and reduction of troublesome and radio-resistant splenic enlargement will follow Myleran treatment in most instances. Myleran is useless in acute leukaemia and in the acute myeloid crisis of chronic leukaemia.

The dose of Myleran should not exceed $4 \mathrm{mg}$. daily. During the second or third week the leucocyte count begins to fall, but normal levels may not be reached before three or four months. The treatment is continued with frequent bloodcount control, provided that the improvement is maintained and that there is no reduction of platelets to less than 100,000 per cu. mm. Higher doses of Myleran are likely to cause thrombocytopenia or general marrow aplasia.

As in TEM, experience is as yet too restricted to be certain that the prolonged administration of Myleran has no deleterious effect on normal marrow function and the use of these drugs might therefore remain confined for the present to cases in which irradiation or nitrogen mustards are contra-indicated or are no longer effective.

Radiotherapy and the present forms of chemotherapy in leukaemia act by a purely repressive or destructive effect on malignant cells. The selectivity of this effect is only one of degree and the hope for the future must lie with the development of methods which will either damage malignant cells exclusively, or better still, restore the normal control-mechanism which regulates mitosis and differentiation of cells in accordance with the needs of the body.

\section{REFERENCES}

I. PUSEY, W. A. (1902), f.A.M.A., 38, $9 \mathrm{r} \mathrm{r}$

2. TROWELL, O. E. (1952), F. Path. \& Bact., 64, 657.

3. HYNES, M. (1939), Lancet, 236, 1373 .

4. GUNZ, F. W. (r953), Blood, 8, 687.

5. MINOT, G. R., et al. (1924), F.A.M.A., 82; 1489.

6. MINOT, G R., et al. (1924), Boston med. F., r91, $\mathrm{x}$.

7. PUFFY, B. J., and HOLLAND, J. W. (1952), N.Y. State $\mathcal{X}$. Med., 42, 551 .

8. LEAR, H., et al. (1950), F.A.M.A., 143, 806.

9. LEVITT, W. M. (1948), in: R. Paterson, 'The Treatment of Malignant Disease by Radium and X-Rays,' London, Edward Arnold.

10. OSGOOD, E. E. (1951), Arch. int. Med., 87, 329.

II. CRAVER, L F. (1948), Bull. N.Y. Acad. Med. (January).

I2. SMITH, I. H. (1953), Canad. med. Ass. F., 68, i, 40.

13. LOW-BEER, B. V. A. (1950), "The Clinical Use of Radioactive Isotopes,' Springfield,' U.S.A.

14. FISHER, J. M., et al. (1952), New Eng. F. Med., 246, 477.

15. PINEY, A. (1948), Blood, 3, 885.

16. HAWKINS, J. A., and MURPHY, J. B. (1925), f. exp. Med., 42, 609 .

17. HADDOW, A., and SEXTON, W. A. (1946), Nature, 157, 500.

18. FEHLINGER, K., et al. (1949), Wien. Zeitschr. Inn. Med., 29, 245.

19. PATERSON, E., et al. (1946), Lancet, i, 677.

20. WATKINS, C., et al. (1948), Blood, 3, 892 .

21. CRESKOFF, A. J., et al. (1948), Ibid., 3, 896:

22. HIRSCHBECK, J. S. (1948), भ.A.M.A., 136, 90.

23. COOPER, T., and WATKINS, C. (1950), Mec. Clin. N. Am., 34, 1205 .

23A. OULER, R. L., et al. (1950), New Eng. med. $\mathcal{f}$., 243, 984.

24. LAWRENCE, P. B., and CARTER, C. E. (1950), ₹. Cell $\xi^{\circ}$ Comp. Phys., 35, 387.

25. WILKINSON; J. F., and FLETCHER, F. (1947), Lancet, ii, 540 .

26. WINTROBE, M., et al. (1947), Annals Int. Med., 27, 529.

27. CRAVER, L. F. (1948), Bull. N.Y. Acc. Med. (January).

28. SPURR, C. L., et al. (1950), Am. F. Med., 8, 7 ro.

29. WILKINSON, J. F. (1953), Proc. roy. Soc. Med., 46, 685.

30. MATHEWS, W. B. (1950), Lancet, i, 896.

31. GARDIKAS, C., and WILKINSON, J. F. (1951), Ibid., i, 137. 32. KARNOFSKI, D. A., et al. (1951), Arch. Int. Med., 87, 477. 33. RUNDLE, R. W., and BARTON, W. B. (1952), Blood, 7, 483.

34. KRAVITZ, S. C., et al. (1952), Ibid., 7, 729.

35. PATERSON, E., et al. (1953), Brit. med. f., i, 59.

36. HADDOW, A., and TIMMIS, G. M. (1953), Lancet, i, 207.

37. GALTON, D. A. (1953), |Ibid, i, 208.

38. GALTON, D. A. (1953), Brit. F. Radiol., 26, 285.

39. LEDLIE, E. M. (1953), Ibid., 26, 290.

\section{Continuation of Bibliography from Page 84-Haemolytic Anaemia, F. G. Selwyn.}

DACIE, J. V. (1949), Blood, 4, 1183.

DACIE, J. V. (1950), F. Path. Bact., 62, 241.

DACIE, J. V., and DE GRUCHY, G. C. (1951), f. clin. Path., 4, 253.

DACIE, J. V., MOLLISON, P. L., RICHARDSON, N., SELWYN, J. G., and SHAPIRO, L. (1953), Quart. F. Med., 22, 79 .

DAMESHEK, W. (1950), New Engl. F. Med., 242, 601.

DAMESHEK, W. (1952), Brit. med. $\mathcal{F}$., ii, 6r2.

FERRIMAN, D. G., DACIE, J. V., KEELE, K. D., and FULLERT@N, J. M. (195I), Quart. F. Med., 20, 275.

JOPE, E. M. (1946), Brit. F. Indust. Med., 3, г 36.

KAPLAN, E., and ZUELZER, W. W. (1950), F. Lab. clin. Med., $36,517$.

KAPLAN, E., ZUELZER, W. W., and NEEL, J. V. (1951), Blood, 6, 1240 .

LONDON, I. M., SHEMIN, D., and RITTENBURG, D. (1950), f. Biol. Chem., 184, 35I.

MILLER, E. B., SINGER, K., and DAMESHEK, W. (1942), Arch. Int. Med., 70, 722.

MOLLISON, P. L., and YOUNG, I. M. (1942), Quart. F. Exp. Physiol., 31, 359 .

NEEL, J. V. (1951), Blood, 6, 389 .
OWREN, P. A. (1948), Ibid., 3, 23 I.

PAULING, L., ITANO, A. H., SINGER, S. J., and WELLS, I. C. (1949), Science, I10, 543 .

PERUTZ, M. F., and MITCHISON, J. M. (1950), Nature, 166, 677.

POWELL, W. N., RODARTE, J. G., and NEEL, J. V. (I950), Blood, 5,887 .

SELWYN, J. G., and HACKETT, W. E. R. (1949), F. clin. Path., 2, 114 .

SHEMIN, D., and RITTENBURG, D. (1946), f. Biol. Chem., I66, 627 .

SINGER, K., RUBIN, S., KING, J., and JEFFERSON, R. (1948), Э.' Lab. clin.'Med., 33, 975.

SINGER, K., CHERNOFF, A. I., and SINGER, L. (I95I), Blood, 6, 4I 3, 429 .

SINGER, K., and FISHER, B. (1953), Blood, 8, 270.

WEBSTER, S. H. (r949), Blood, 4, 479.

WELlS, I. C., and I'TANO, A. H. (1950), Federation Proc., 9, 245.

YOUNG, L. E., IZZO, M. J., and PLATZER,'R. F. (I95 ra), Blood, 6, 1073 .

YOUNG, L. E., PLATZER, R. F., ERVIN, D. M., and IZZO, M. J. (195 Ib), Blood, 6, 1099. 